\section{Lower eyelid tensometry in younger and older normal subjects}

${ }^{1}$ The Ocular Plastics Unit, The Prince of Wales Hospital and the University of New South Wales, Sydney, Australia

${ }^{2}$ School of Optometry and Vision Science and CRCERT, University of New South Wales, Sydney, Australia

Correspondence: IC Francis Suite 12, Chatswood Grove 12-14 Malvern Ave Chatswood. 2067 NSW Australia

Tel: + 61294113277 ;

Fax: +61294131839 .

E-mail: if@

student.unsw.edu.au

Received: 19 September 2004

Accepted: 1 December 2004

Published online: 4 March 2005.

Meeting presentation: Presented at the annual meeting of the Association for Research and Vision in Ophthalmology in Fort Lauderdale, Florida, 2001. Financial Support: The study was partly supported by Allergan Australia; the British Contact Lens Association (Da Vinci Award to Dr Ehrmann for the development and validation of the eyelid tensometer); and the Australian Federal Government through the Cooperative Research Centres Program

Proprietary interest: None

\begin{abstract}
Purpose This study aimed to establish normative and repeatability data for lower eyelid tensometry (LET) using a newly developed eyelid tensometer.

Methods In this prospective consecutive observational case series, 32 normal adult subjects, comprising 12 younger (aged $29 \pm 5$ years, $6 \mathrm{M}: 6 \mathrm{~F}$ ) and 20 older subjects (aged $74 \pm 6$ years, 10M:10F), underwent LET. In the younger group, LET was measured for posteroanterior (PA), nasal and temporal displacement. Duplicate measurements were taken and these were repeated on a separate occasion. Associations between repeated measurements and between right and left eyes were determined and the coefficient of repeatability for PA measurements was estimated. Differences in LET between males and females were determined using ANOVA. Only PA tensions, with duplicate measurements, were assessed in the older group, and age effects were determined.

Results Mean temporal tension in the younger group was $7.8 \pm 2.9 \mathrm{mN}$ (milliNewtons)/mm, while nasal tension was $13.0 \pm 4.6 \mathrm{mN} / \mathrm{mm}$ and PA tension was $11.2 \pm 5.3 \mathrm{mN} / \mathrm{mm}$. There was a good correlation between interoccasion PA measurements $(r=0.82-0.84, P<0.005)$ and between the right and left eyes $(r=0.48$, $P<0.005)$. The coefficient of repeatability for PA tension was $1.8 \mathrm{mN} / \mathrm{mm}$. In the younger group, overall eyelid tension (for all directions) for males was significantly higher than for females (ANOVA, $P=0.03$ ). For measurements in older subjects on a single occasion, PA tension was $11.1 \pm 3.5 \mathrm{mN} / \mathrm{mm}$ and in younger subjects $12.8 \pm 4.2 \mathrm{mN} / \mathrm{mm}$ $(P=0.22)$.

Conclusions LET is rapid, repeatable, feasible, and acceptable. PA tension was the
\end{abstract}

IC Francis ${ }^{1,2}$, F Stapleton ${ }^{2}$, K Ehrmann ${ }^{2}$ and MT Coroneo ${ }^{1,2}$ most repeatable measurement. Younger males had higher eyelid tension than females, and there was no significant reduction in PA tension with age.

Eye (2006) 20, 166-172. doi:10.1038/sj.eye.6701830 published online 4 March 2005

Keywords: lower eyelid tension; repeatability; human

\section{Introduction}

Eyelid tension is an important factor in the pathogenesis of many acquired lid diseases. Adequate upper lid tension is important in maintaining normal lid-tear resurfacing ${ }^{1}$ mechanisms and in preventing ocular exposure. Upper eyelid tension has been shown to decrease with age. ${ }^{2}$ Floppy eyelid syndrome ${ }^{3}$ is an example of functional loss where upper lid tension is reduced. Reduced lower eyelid tension is a significant factor in the pathogenesis of involutional ectropion and entropion. ${ }^{4}$ In patients with watery eyes, lower eyelid tension may be reduced. 5,6

Lid tension has been evaluated using mechanical $^{7-10}$ and ultrasonic techniques ${ }^{11}$ to quantify upper lid tension, but lower eyelid tensometry (LET) has previously been evaluated using subjective techniques only. ${ }^{12,13}$ To our knowledge, there are no published data on the magnitude of human lower eyelid tension.

In physical terms, tension is defined as the first derivative of the force over displacement function of any elastic material under stress. For the purpose of this study, the measurement principle is based on displacing the lid while recording exerted force as a function of displaced distance.

Determination of lid tension is clearly relevant in determining the natural history of 
lid disease, and in ocular plastic surgery. The aim of this study was to establish normative data and intra- and inter-occasion repeatability data for LET for displacement in the postero-anterior (PA), temporal, and nasal directions in younger normal subjects, to examine the effect of age on PA eyelid tension, and to establish the effect of gender on eyelid tension in age-matched subjects.

\section{Materials and methods}

\section{Instrumentation}

A novel eyelid tensometer designed and built to measure eyelid tension objectively was used in this study. The instrument comprises an eyelash clamp device, two stepper motors, two force transducers, an electronic interface box, and computer for instrument control and data acquisition, and a patient fixation device (Figure 1). The instrument was validated and calibrated in an earlier study ${ }^{14}$ by measuring the force and displacement values using a series of weights covering the measurement range of $5 \mathrm{mN}$ (milliNewtons) to $2 \mathrm{~N}$. Validation and calibration were carried out to correct for systematic errors, to verify measurement accuracy, to confirm linearity of the force transducers across the measurement range, and to demonstrate that any effect of hysteresis was negligible.

\section{Subject selection}

A total of 32 Caucasian subjects were selected to participate in the study. The younger age group (Group $1, n=12$ ) comprised six males and six females with a

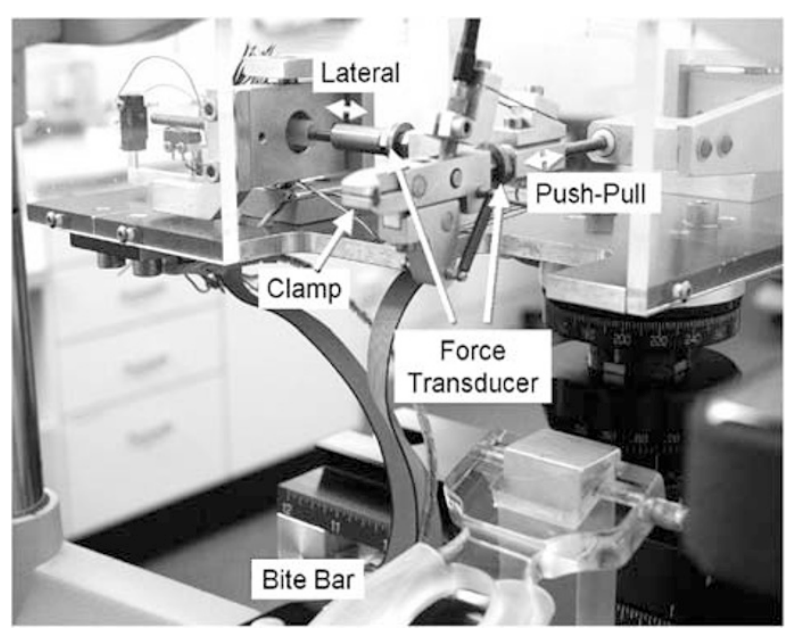

Figure 1 Eyelid tensometer instrument. mean age of 29 years (range 23-37). The older age group (Group 2, $n=20$ ) comprised 10 males and 10 females with a mean age of 74 years (range 61-81). The subjects had no pre-existing ocular pathology, reported no eye symptoms and were using no topical medication. The investigation was conducted in accordance with the tenets of the Declaration of Helsinki. Written consent was obtained following explanation of the study procedure. Approval for the procedures from the University of New South Wales Ethics Committee was obtained prior to the investigation.

\section{Study design}

Group 1: LET was carried out on each subject on two occasions, several days apart. Each measurement was carried out twice within each occasion. The lash clamp was not removed between different eyelid movements unless the subject expressed discomfort.

Group 2: PA tension only was measured on each subject on a single occasion. Two measurements were taken for each eye.

\section{Procedures}

The subject was seated at the tensometer, and the machine action explained. The side of LET to be performed first was decided by the toss of a coin. The subject was then asked to bite firmly onto the tensometer bite bar, and to rest the forehead securely onto the forehead rest of the tensometer. The chinrest was adjusted so that the subject was comfortable and the head completely steady on the tensometer. Topical anaesthesia was not used and subjects were asked to relax their lids as far as possible during the assessment. The lower eyelid lashes were clamped in the midpupillary line using the eyelash gripper (Figure 2), and eyelid tension neutralised by observation initially by the operator, and then electronically.

For Group 1, LET was performed in the PA, temporal, and nasal directions, with a maximum force of $0.7 \mathrm{~N}$, a maximum displacement of $3.5 \mathrm{~mm}$, and with the speed of displacement being $1 \mathrm{~mm} /$ second. That is, the lash clamp was moved in the PA, temporal, and nasal directions to displace the lid away from the globe anteriorly (PA), and perpendicularly to the visual axis for the temporal and nasal directions of tension, respectively. Forward force displacement data were captured for analysis. The second eye was then similarly measured. On the second occasion, the LET measurements were repeated using the contralateral eye first. Eyelid tension in $\mathrm{mN} / \mathrm{mm}$ was calculated as the slope of the best-fit linear curve over the full displacement range. 
For both groups over this displacement range, tension measurements were adequately fitted using a linear curve fit, since increased and nonlinear tension were observed with displacements larger than $3.5 \mathrm{~mm}$.

\section{Data analysis}

There were differences in the handling of the data between the two subject groups. The younger group was utilised for multiple and repeated measurements to establish repeatability of the eyelid tension measurements, gender effects for a range of directions and to establish the effects of laterality. These findings informed the data collection for the older age group. Thus, duplicate measurements were taken for a single displacement direction (PA) on a single occasion in the older age group, as PA proved to be the most highly correlated direction for LET.

Group 1: Associations between measurements made on occasions 1 and 2 and between right and left eyes were examined using Pearson's parametric correlation. The

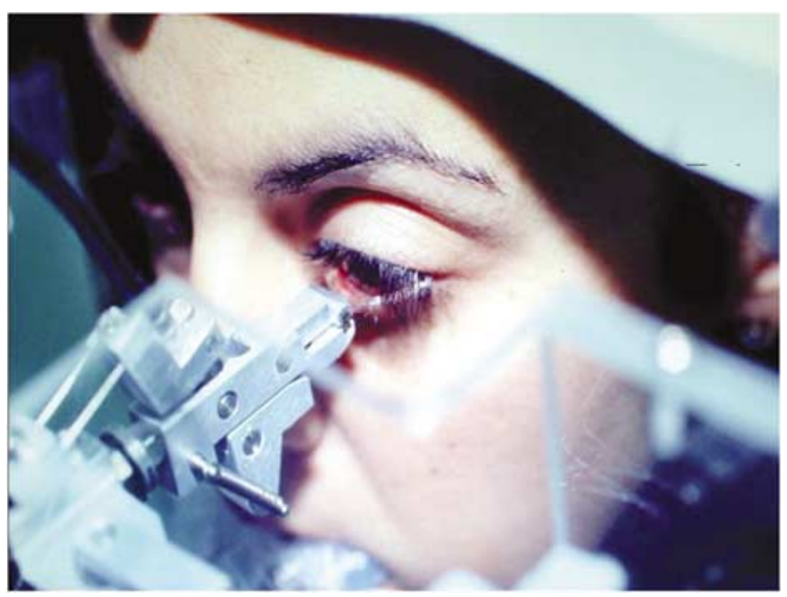

Figure 2 Eyelash clamp attached to the patient's lower eyelid during eyelid tensometry. coefficient of repeatability was estimated as $2.20 \times$ the within-subject standard deviation. ${ }^{15}$ Comparisons between males and females were made using a one-way ANOVA.

Group 2: The mean PA tension for the right and left eyes was estimated. Gender and age effects between groups 1 and 2 were examined using a grouped $t$-test.

\section{Results}

\section{General results}

For all younger subjects (Group 1), the mean tension for temporal displacement (temporal tension) was $7.8 \pm 2.9 \mathrm{mN} / \mathrm{mm}$, nasal displacement (nasal tension) was $13.0 \pm 4.6 \mathrm{mN} / \mathrm{mm}$, while PA tension was $11.2 \pm 5.3 \mathrm{mN} / \mathrm{mm}$. Nasal displacement was significantly higher than temporal $(P<0.005)$. In the older subject group (Group 2), mean PA tension was $11.1 \pm 3.4 \mathrm{mN} / \mathrm{mm}$. Differences in PA tension with age were not significant (Table 1).

\section{Laterality effects}

There was moderate correlation between PA measurements from the right and left eyes, where $r=0.48, P=0.001$. Nasal and temporal tension measurements were not well correlated between the right and left eyes $(P>0.05)$. The order of testing did not influence the eyelid tension: in other words, whether the right or left eye was tested first did not influence the test result.

\section{Interoccasion repeatability}

Measurements of PA tension in Group 1 appeared to be highly correlated between occasions (right eye, $r=0.82$, $P<0.005$ (Figure 3); left eye, $r=0.84, P<0.05$ ). Agreement between the two repeats is shown in Figure 4 . The coefficient of repeatability, defined as $2.20 \times$ the withinsubject standard deviation ${ }^{15}$ for PA measurements, was $1.8 \mathrm{mN} / \mathrm{mm}$, which is the value below which the

Table 1 Mean postero-anterior (PA) eyelid tension with age and gender

\begin{tabular}{|c|c|c|c|c|}
\hline Lid tension $(\mathrm{mN} / \mathrm{mm})$ & Younger subjects $(\mathrm{n}=12)$ & Older subjects $(\mathrm{n}=20)$ & $\mathrm{P}$-value ${ }^{\mathrm{a}}$ & All subjects $(\mathrm{n}=32)$ \\
\hline Males $(n=16)$ & $14.8 \pm 5.1$ & $12.2 \pm 4.0$ & 0.22 & $13.2 \pm 4.8$ \\
\hline Females $(n=16)$ & $10.7 \pm 1.8$ & $10.0 \pm 2.4$ & 0.53 & $10.3 \pm 2.3$ \\
\hline$P$-value ${ }^{\mathrm{b}}$ & 0.03 & $0 . \overline{15}$ & - & 0.04 \\
\hline All subjects & $12.8 \pm 4.2$ & $11.1 \pm 3.5$ & 0.22 & $11.8 \pm 4.0$ \\
\hline
\end{tabular}

aTwo-tailed grouped $t$-test, comparing younger and older subject groups.

${ }^{\mathrm{b}}$ Two-tailed grouped $t$-test, comparing males and females.

Differences at the 95\% level are shown in bold. 
difference between two repeated measurements would be expected to fall with $95 \%$ probability.

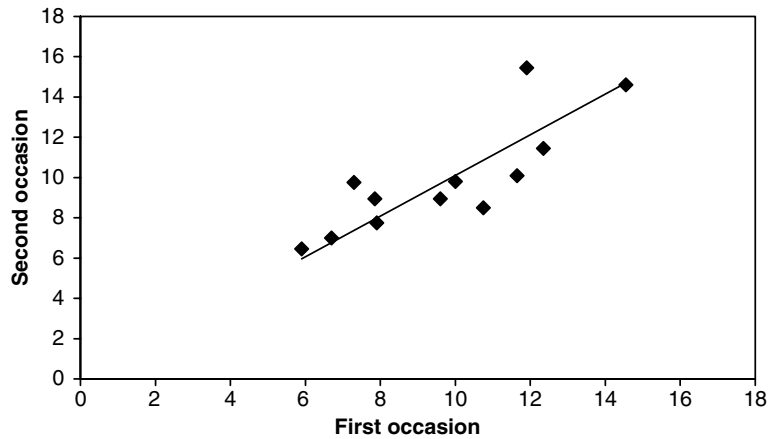

Figure 3 Graph showing interoccasion variability in PA tension in Group 1. A good correlation is shown between measurements taken on two occasions, $r=0.821, P=0.001$.

\section{Nasal and temporal displacement}

Individual subject data for nasal and temporal displacement in Group 1 were not well correlated with each other $(P>0.05)$, and the correlation between measurements on two occasions did not reach statistical significance.

\section{Gender effects}

Group 1: For measurements taken on a single occasion, younger males were found to have significantly higher eyelid tension (in all directions) than younger females (ANOVA, $P=0.03$, Figure 5). Mean PA tension in females was $10.7 \pm 1.8 \mathrm{mN} / \mathrm{mm}$ and in males $14.8 \pm 5.1 \mathrm{mN} / \mathrm{mm}$ $(P=0.03)$ (Table 1$)$.

Group 2: In the older subjects, gender did not appear to influence PA tension. Mean PA tension in females was

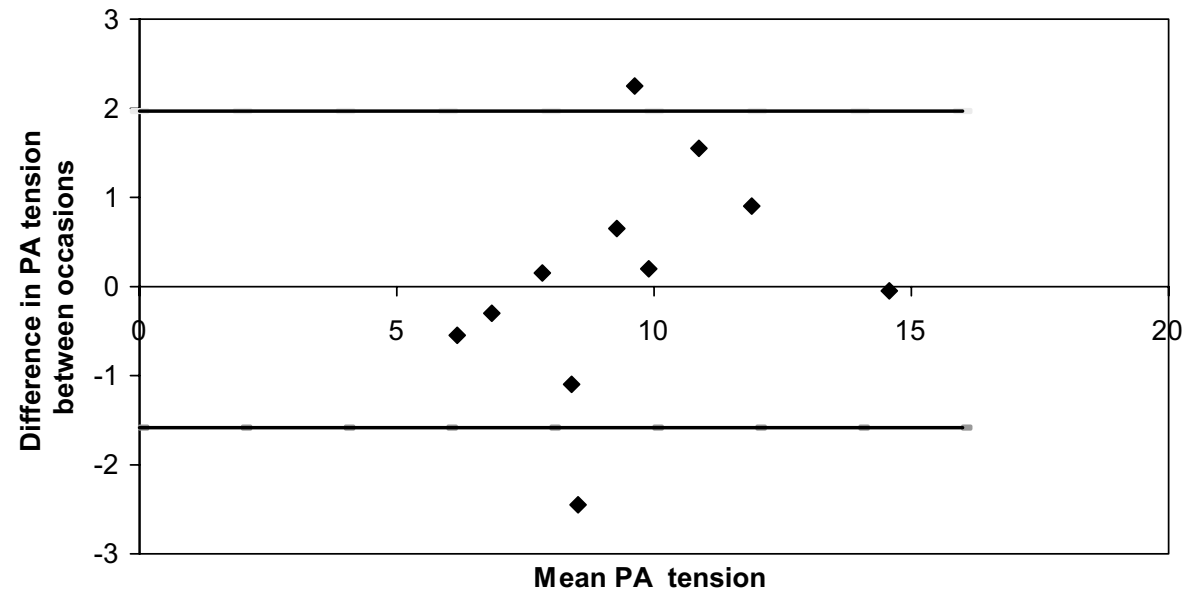

Figure 4 Graph showing agreement between two repeated measures for PA displacement in Group 1. Difference between the two measurements is plotted against the mean. The solid lines show the coefficient of repeatability for two repeated PA displacement measurements. Bias is $-0.19 \mathrm{mN} / \mathrm{mm}$ and $95 \%$ confidence intervals $\pm 1.77 \mathrm{mN} / \mathrm{mm}$.

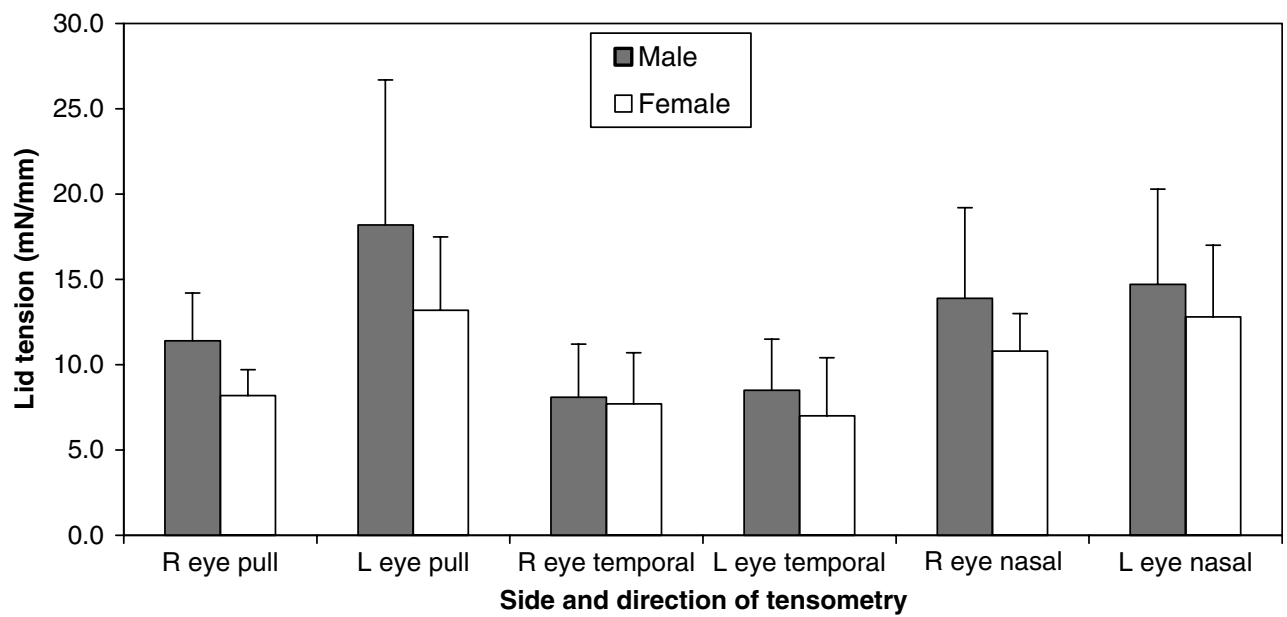

Figure 5 Graph showing mean and standard deviation for male and female tensions in Group 1 for PA, nasal and temporal displacement. 
$10.0 \pm 2.4 \mathrm{mN} / \mathrm{mm}$ and in males $12.2 \pm 4.0 \mathrm{mN} / \mathrm{mm}$ $(P=0.15$, Table 1$)$.

\section{Discussion}

This study presents for the first time normative, reproducibility, and gender difference data in LET. Both younger and older adult populations were studied.

Previous studies in eyelid tensometry have measured the force required to move the upper eyelid, in contrast to the lower eyelid, in a PA direction, or the force generated by the levator muscle. ${ }^{7-10}$ To our knowledge, lower eyelid tension has not been measured previously except by clinical $^{4,12,13}$ means.

Mean lower eyelid tension for all subjects ranged between 7.8 and $14.8 \mathrm{mN} / \mathrm{mm}$ and nasal displacement tension was significantly higher than temporal displacement. Mean PA tension for all subjects ranged between 10.0 and $14.8 \mathrm{mN} / \mathrm{mm}$, and the magnitude of this tension measurement is consistent with that reported for the upper eyelid by Vihlen and Wilson. ${ }^{2}$

PA displacement in the present study was slightly less than nasal tension but higher than temporal tension. The fact that the PA tension was higher than temporal tension may reflect the reflex orbicularis contraction when the eyelid is moved away from the globe during PA displacement. Theoretically, the orbicularis oculi will be contracting on both sides of the lash clamp in the PA movement, while on temporal displacement, only the side of the orbicularis opposite to the direction of tensometry (the nasal orbicularis) may be contracting. On the other hand, we speculate that the nasal tension may be higher than the temporal tension because the greater bulk of the orbicularis is found lateral to the midpupillary line, ${ }^{16}$ the site at which the eyelid was grasped by the tensometer lash clamp. However, this result is unexpected, as the normal movement of the lower eyelid during blinking is in the nasal direction, suggesting that the tension generated by the nasal fibres should be greater than that generated by those of the temporal side. ${ }^{16}$ The inter-eye correlation in PA measurement was moderate, as has been previously reported for upper eyelid measurements. ${ }^{2}$

We have demonstrated that there is a high interoccasion correlation in lower eyelid tension for PA displacement, but not for either nasal or temporal displacement. The poorer repeatability with lateral (nasal and temporal) displacements may reflect bending of the lashes when moving the eyelid perpendicular to the visual axis/lashes. The variances for repeated occasion measurements in PA tension were similar and, as expected, the main variability in the current measurement is attributed to the between-subject variability. Coefficient of repeatability data will assist in gauging meaningful differences between population groups using this technique. Our data would suggest that measurement of lower lid PA tension offers reasonable discriminatory ability.

Consistently higher lid tension for all displacements was reported in younger males compared with younger females. A similar gender difference in upper lid tension has been reported. ${ }^{17}$ The reason for these differences is unknown, but the higher tension in males may reflect the greater muscle bulk in males compared with females. There was also greater variability in PA measurements in males. Interestingly, this finding was not reflected in the older group, although the power to detect differences was low (0.244). While not statistically significant, we would speculate that the greater muscle bulk in males may reduce with age. Based on the mean standard deviation, and using the coefficient of repeatability as the estimate of minimum detectable difference between groups, power of $80 \%$ and $\alpha=0.05$, a sample size of 89 subjects per group of young and older males would be required to confirm the age effect in males. Thus a total sample of 178 subjects ( 89 young and 89 old) would be required to establish that eyelid tension decreases with age in males.

It was curious and reassuring that once the subject had his/her bite on the bite bar established, along with the forehead and chin firmly resting on the forehead rest and chin rest respectively, there was almost never any demonstration of blepharospasm or withdrawal. We suspect that this type of absolute head fixation, largely engendered by the effect of the bite bar, has a very reassuring effect on the subject, and may thereby prevent unwanted voluntary or involuntary subject movement, and in particular eyelid movement. It is certainly different from the clinician's experience when using the customary slit lamp, where the patient frequently moves quite regularly. By inspecting the slope of lid tension on the tensometer computer screen, and glancing at the subject's position in space and in particular in relation to the forehead rest, it was possible to recognise the rare occasion, which suggested that the patient had withdrawn and produced a falsely high tensometry reading. The subjects uniformly responded willingly to instructions given both before and during their time on the lid tensometer.

The findings of this study may have relevance to surgeons involved in eyelid plastic surgery, particularly since the lower eyelid is more frequently operated upon than the upper eyelid in populations exposed to high levels of ultraviolet radiation. Examples of such conditions requiring lower eyelid surgery include involutional, tarsal or cicatricial ectropion, involutional entropion, lower eyelid neoplasms, some types of watery eyes, ${ }^{6}$ as well as eyelid abnormalities associated with 
thyroid orbitopathy. Ophthalmic surgeons have always operated on the lower eyelid based on a clinical assessment of the laxity of both medial and lateral canthal tendons. We have recently reported on a clinical classification of canthal tendon laxity. ${ }^{18,19}$ Clinical assessment also involves an estimation of the eyelid's PA elasticity using the 'snap back test' ${ }^{20}$ and an estimate of eyelid distraction..$^{20}$ The tension of the lower eyelid must be adjusted accurately at surgery to avoid excessive horizontal eyelid tightening, which could cause lower eyelid ptosis. In the future, an awareness of normal and abnormal lower eyelid tension, as measured by an objective test, may allow the surgeon to plan eyelid surgery more effectively.

Other applications of eyelid tensometry could include the assessment of patients with upper eyelid disorders, such as those having floppy eyelid syndrome, superior limbic keratoconjunctivitis (SLK), and some patients with contact lens difficulties. ${ }^{21}$ Specifically, eyelid tension may influence contact lens centration, movement, and rotational stability. In these clinical settings, one would expect to see a variation in eyelid tension, the eyelid being looser in the floppy eyelid syndrome and involutional ectropion, and being increased in some patients with contact lens difficulties and SLK. In addition, the impact of eyelid tension on corneal topography has been raised as a significant issue, especially in refractive surgery. Eyelid retraction by the eyelid speculum during refractive surgery may alter corneal power by a significant amount compared with the presurgical measurement, and this may impact the refractive outcome. ${ }^{22}$

Eyelid tension in older normal adults was shown in this pilot study to demonstrate no significant reduction compared with younger normal adults, although the power to detect differences was low (0.299). This lack of effect might suggest that the presumed collagen failure of the lower eyelid with increasing age $e^{23}$ does not significantly contribute to its reduction. By contrast, it may be that the effect of UV radiation ${ }^{24}$ in stiffening the anterior, or weather-exposed, lamella of the lower lid accounts for this. However, testing a range of ages using a larger sample size would be appropriate to investigate further these effects. Our LET information will be used in further studies for comparison with LET measured in patients with both anatomical and functional nasolacrimal duct obstruction, since the multifactorial nature of the functional cases ${ }^{17,25}$ may allow us insight into more directed and precise management of this cause of watery eyes.

In summary, this study has reported normative data for tension in the lower eyelid. It has demonstrated lower eyelid tension, and specifically PA displacement tension, can be accurately measured and is repeatable. While it has also shown that eyelid tension in young males is higher than in young females, gender differences in PA tension were not apparent in older subjects. In this pilot study, PA tension does not appear to reduce significantly with age.

\section{Acknowledgements}

We thank Mr Reg Wong for statistical advice, and Dr Shanel Sharma for editorial assistance. This study was partly supported by Allergan Australia, the British Contact Lens Association, and the Australian Federal Government through the Cooperative Research Centres Program.

\section{References}

1 Hurwitz JJ (ed). The Lacrimal System. Lippincott-Raven Publishers: New York, 1996 p 6.

2 Vihlen FS, Wilson G. The relation between eyelid tension, corneal toricity and age. Invest Ophthalmol Vis Sci 1983; 24: 1367-1373.

$3 \mathrm{McNab}$ AA. Floppy eyelid syndrome and obstructive sleep apnea. Ophthalmic Plast Reconstr Surg 1997; 13: 98-114.

4 Hill JC. An analysis of senile changes in the palpebral fissure. Can J Ophthalmol 1975; 10: 32-35.

5 McCord CD, Codner MA, Hester TR. Eyelid Surgery. Principles and Techniques. Lippincott-Raven Publishers: New York, 1995 p 80.

6 Vick VL, Holds JB, Hartstein ME, Massry GG. Tarsal strip procedure for the correction of tearing. Ophthalmic Plast Reconstr Surg 2004; 20: 37-39.

7 Farbowitz M, Furst H, Kastner R, Patel N, Jacoby J. Effect of Diltiazem during light - flash - induced blinks in the rabbit. Invest Ophthalmol Vis Sci 1993; 34: 293-304.

8 Frueh BR, Musch DC. Levator force generation in normal subjects. Trans Am Ophthalmol Soc 1990; 88: 109-121.

9 Hung G, Hsu F, Stark L. Dynamics of the human eyeblink. Am J Optom Physiol Opt 1977; 54: 678-690.

10 Straub W, Backhaus J. Objective lid strength measurements in various eye diseases. Klin Monatsbl fur Augenheilk 1970; 156: $230-235$.

11 Obrubov SA, Sidorenko EI, Molotkov AP, Fedorova VN. Biomechanical irregularities in the distribution of tension in various zones of the eyelids in health and myopia of different degrees. Vestnik Oftalmologii 1996; 112: 24-27.

12 Shore JW. Changes in lower eyelid resting position, movement and tone with age. Am J Ophthalmol 1985; 99: 415-423.

13 Swarbrick HA, Holden BA. Ocular characteristics associated with rigid gas-permeable lens adherence. Optom Vis Sci 1996; 73: 473-481.

14 Ehrmann K, Francis I, Stapleton F. A novel instrument to quantify the tension of upper and lower eyelids. Contact Lens Anterior Eye 2000; 24: 65-72.

15 Bland JM, Altman DG. Statistical methods for assessing agreement between two methods of clinical measurement. Lancet 1986; 1(8476): 307-310.

16 Bron AJ, Tripathi RC, Tripathi BJ. Wolff"s Anatomy of the Eye and Orbit, 8th Ed. Chapman and Hall Medical: Melbourne, 1997, pp 47-49. 
17 Köhler U, Müller $\mathrm{CH}$. Ein neues Gerät zur Messung der Lidkraft. Klin Mbl Augenheilk 1991; 199: 53-56.

18 Francis IC, Wilcsek GA, Sharma S, Coroneo MT Transcaruncular medial orbitotomy for stabilisation of the posterior limb of the medial canthal tendon. Clin Exp Ophthalmol 2001; 29: 85-92.

19 Francis IC. Canthus-sparing ectropion repair. Ophthalmic Plast Reconstr Surg 2002; 18: 311-312.

20 Hurwitz JJ (ed). The Lacrimal System. Lippincott-Raven Publishers: New York, 1996, p 49.

21 Lydon D, Tait A. Lid-pressure: its measurement and probable effects on the shape and form of the cornea-rigid contact lens system. J Br Contact Lens Assoc 1988; 1: 11-22.
22 Lieberman DM, Grierson JW. The lid's influence on corneal shape. Cornea 2000; 19: 336-342.

23 Bailey AJ. Molecular mechanisms of ageing in connective tissues. Mech Ageing Dev 2001; 122: 735-755.

24 Wollensak G, Spoerl E, Seiler T. Stress-strain measurements of human and porcine corneas after riboflavin-ultraviolet-Ainduced cross-linking. J Cataract Refract Surg 2003; 29: 1780-1785.

25 Conway ST. Evaluation and management of "functional" nasolacrimal blockage: results of a survey of the American Society of Ophthalmic Plastic and Reconstructive Surgery. Ophthalmic Plast Reconstr Surg 1994; 10: 185-188. 